\title{
Sex Differences in Stroke Rehabilitation Care in Alberta
}

\author{
Eric Tanlaka (D, Kathryn King-Shier, Theresa Green, Cydnee Seneviratne, \\ Sean Dukelow (iD
}

\begin{abstract}
Background: Female stroke patients may experience poorer functional outcomes than males following inpatient rehabilitation. Methods: Data from Alberta inpatient stroke rehabilitation units were examined to determine: (1) the impact of sex on time to inpatient rehabilitation, functional gains (using the Functional Independence Measure (FIM)), length of stay (LOS), and discharge destination; (2) if sex was related to age at the time of stroke, stroke severity, and living arrangement at discharge from rehabilitation; and (3) whether patients' age and preadmission living arrangement had an influence on LOS in rehabilitation or discharge destination. Results: Two thousand two hundred sixty-six adult stroke patients (1283 males and 983 females) were subcategorized as mild (FIM >80; $n=1155$ ), moderate (FIM 40-80; $n=994$ ), or severe (FIM <40; $n=117$ ). Fifty-five percent of males ( $45.7 \%$ females) had mild stroke; $39.5 \%$ of males ( $49.5 \%$ females) had moderate stroke; and $5.5 \%$ of males $(4.8 \%$ females) had severe stroke. Females were significantly older than males $\left(p=2.4 \times 10^{-4}\right)$. No sex difference existed in time from acute care to rehabilitation admission $(p=0.73)$ or in mean FIM change $(p=0.294)$. Mean LOS was longer for females than males $(p=0.018)$. Males were more likely than females to be discharged home $\left(p=1.8 \times 10^{-13}\right)$. Further, male patients $\left(p=6.4 \times 10^{-7}\right)$ and those $<65$ years $\left(p=1.4 \times 10^{-23}\right)$ were more likely to be discharged home without homecare. Conclusion: There are significant sex and age differences in LOS in rehabilitation and discharge destination of stroke patients. These differences may suggest that sex and age of the patient need to be considered in care planning.
\end{abstract}

RÉSUMÉ : Différences entre les hommes et les femmes admis dans un centre de soins de réadaptation destinés en Alberta à des victimes d'AVC. Contexte : Une fois des soins de réadaptation prodigués en milieu hospitalier, il semble que les femmes victimes d'AVC donnent à voir une évolution de leur autonomie fonctionnelle plus difficile que celle des patients de sexe masculin. Méthodes : Des données albertaines fournies par des unités de réadaptation destinées à des patients victimes d'AVC ont été ainsi examinées afin de déterminer : (1) l'impact du sexe en ce qui concerne les délais d'obtention de soins de réadaptation en milieu hospitalier, leurs gains fonctionnels (au moyen de la mesure de l'indépendance fonctionnelle ou MIF), leur durée de séjour et leur destination après l'obtention d'un congé ; (2) si la variable du sexe était reliée à l'âge des patients au moment d'un AVC mais aussi à sa gravité et à leurs conditions de vie au moment d'obtenir leur congé ; (3) dans quelle mesure l'âge des patients et leurs conditions de vie avant d'être admis avaient un impact sur la durée de leur séjour en réadaptation ou sur leur destination respective une fois leur congé obtenu. Résultats : Au total, 2266 patients adultes (1283 hommes et 983 femmes) ont été retenus aux fins de cette étude. De ce nombre, 1155 ont été catégorisés comme « légers » en vertu de la MIF (MIF > 80) ; 994 ont été catégorisés comme « modérés » (MIF 40-80); alors que 117 ont été catégorisés comme « sévères » $(\mathrm{MIF}<40)$. Ajoutons que $55 \%$ des hommes ont été victimes d'AVC dits « légers » $(45,7 \%$ de femmes $)$; ils ont été $39,5 \%$ à être victimes d'AVC dits « modérés » (49,5\% de femmes) ; enfin, seulement 5,5\% d'hommes ont été victimes d'AVC dits « sévères » $\left(4,8 \%\right.$ de femmes). Les femmes, soulignons-le, se sont révélées notablement plus âgées que les hommes $\left(p=2,4 \mathrm{x} 10^{-4}\right)$. Aucune différence entre les sexes n'a émergé en ce qui concerne le temps s'étant écoulé entre l'admission aux soins intensifs et le début de la réadaptation $(p=0,73)$ ou en ce qui concerne les changements moyens à la $\operatorname{MIF}(p=0,294)$. Cela dit, la durée moyenne de séjour s'est avérée plus longue pour les femmes $(p=0,018)$. De leur côté, les hommes étaient plus susceptibles que les femmes de prendre le chemin de la maison une fois leur congé obtenu $\left(p=1,8 \times 10^{-13}\right)$; les patients de sexe masculin $\left(p=6,4 \times 10^{-7}\right)$, de même que ceux et celles âgés de moins de 65 ans $\left(p=1,4 \times 10^{-23}\right)$, étaient aussi plus susceptibles de retourner chez eux sans avoir besoin de soins à domicile. Conclusion : Il existe des différences notables en ce qui regarde l'âge et les sexes pour la durée des soins en réadaptation et la destination après avoir obtenu un congé. De telles différences semble suggérer que le sexe et l'âge des patients doivent être pris en compte dans la planification des soins.

Keywords: Stroke, Sex differences, Inpatients, Rehabilitation, Recovery of function, Length of stay doi:10.1017/cjn.2020.53

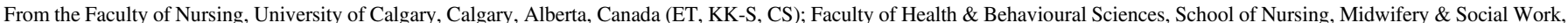

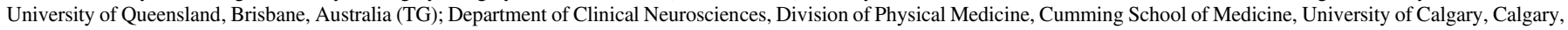
Alberta, Canada (SD)

Received November 13, 2019. Final Revisions Submitted February 18, 2020. Date of Acceptance March 5, 2020.

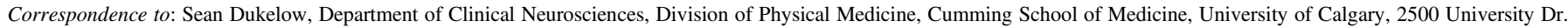
NW, Calgary, Alberta, Canada T2N 1N4. Email: spdukelo@ucalgary.ca 


\section{INTRODUCTION}

Males and females with stroke in Canada have equal access to core rehabilitation services including physical therapy, occupational therapy, and speech therapy. ${ }^{1-3}$ Despite equal access to these services, differences in functional outcomes of male and female stroke patients have been previously reported. ${ }^{3}$ Studies from other countries have suggested that female stroke patients experience poorer functional outcomes than male stroke patients following inpatient rehabilitation. ${ }^{2,4-9}$ Variations have been attributed to the fact that females with stroke have more physical impairments and limitations in performance of daily living activities after stroke relative to males. ${ }^{2,5,8}$ Similarly, when males and females were matched for age, severity of stroke, and time to rehabilitation admission, males demonstrated greater independence in stair climbing and performance of daily living activities compared to females. $3,5,9$ This finding has been attributed to increased androgen receptors in the upper body of males, leading to higher levels of testosterone that stimulate upper body muscle development and increase upper body muscle mass in male compared to female patients. ${ }^{10}$

Certain factors may contribute to poorer functional outcomes in female stroke patients following rehabilitation. In previous large Canadian $(n=3323)$ and Danish $(n=26,818)$ studies, examinations of sex differences in disability, length of stay (LOS), and discharge destination of poststroke patients have shown that female stroke patients experience greater disability at 6 months poststroke, have longer LOS in rehabilitation, and are more likely to be discharged to a long-term care facility compared to male stroke patients. ${ }^{2,6}$ These differences were attributed to decreased physical function prior to rehabilitation admission, reduced independence in performance of daily living activities, lack of social support, lack of spouse/partner, ${ }^{2,4}$ history of stroke, increased body mass index, increased stroke severity, and nursing home residence prior to stroke onset. ${ }^{11}$

In this study, we examined the differences in functional gains, LOS, and discharge destination of male and female stroke patients undergoing inpatient rehabilitation in Alberta. Further, we examined whether patient's age and living arrangement prior to stroke had an influence on their discharge destination, whether patient's sex was related to age at acute care admission, stroke severity, and living arrangement at discharge from rehabilitation, and whether age influenced LOS in rehabilitation. We hypothesized that female sex would be related to worse functional gains, longer LOS, and higher rates of discharge to living environments that provided higher levels of assistance with daily activities. We also hypothesized that increased age and living without a spouse or partner at the time of admission would lead to discharge to living settings that provide additional care to patients.

\section{Methods}

\section{Research Design}

We conducted an analysis of primary data from a cohort of patients admitted to and discharged from inpatient stroke rehabilitation units in Alberta between April 2013 and March 2017. Data were obtained from the Alberta Health Services' stroke rehabilitation database. The study was approved by the University of Calgary's Conjoint Health Research Ethics Board (REB17-1186).

\section{Sample and Setting}

We included all clinically diagnosed cases of adult stroke (hemorrhagic or ischemic) with a documented sex type and inpatient rehabilitation unit stay in Alberta. In cases when the type of stroke at initial acute care presentation was ischemic and there was an eventual hemorrhagic component, we considered "hemorrhagic" as their stroke etiology. We excluded 454 cases from the original dataset provided by Alberta Health Services ( $n=2720$ cases) due to missing data $(n=204)$; cases classified with admission/ discharge living setting listed as boarding house $(n=13)$, shelter $(n=2)$, or public place $(n=63)$; and cases with unspecified pre/post discharge living arrangement $(n=172)$. Cases with these post discharge living settings were excluded because such discharge destinations were considered temporal and could be changing, thus preventing continuous follow-up of patients after discharge.

\section{Instruments}

The Functional Independence Measure (FIM) was used to assess function at time of admission and discharge from the rehabilitation unit. FIMs were completed by rehabilitation unit staff at each of the nine centers providing data within $72 \mathrm{~h}$ of admission to the inpatient rehabilitation unit. Stroke severity was classified based on FIM admission scores. Scores of $<40$ were considered severe, 40-80 were considered moderate, and $>80$ were considered mild. ${ }^{12,13}$ The FIM has been tested for reliability, validity, responsiveness to change, feasibility for use, and meaningfulness in clinical settings when administered by trained and tested personnel. ${ }^{14}$ We defined FIM change as the difference between admission and discharge total FIM scores. We defined FIM efficiency as the mean FIM change divided by the mean LOS in days. Other information collected from the Alberta Stroke Rehabilitation database included: age, sex, preadmission comorbid conditions, patient's living arrangement at discharge from inpatient rehabilitation (living with spouse/partner, living with family, living with nonfamily - unpaid, living with paid attendant, living alone, living in facility, and living in acute care), LOS in rehabilitation units, and patient's post discharge living setting (home without health services, home with paid health services, assisted living, residential care, and acute care).

\section{Data Collection}

Data for the Alberta Stroke Rehabilitation Databases were assembled from Alberta Health Services Provincial Inpatient Discharge Abstract Database, National Rehabilitation System, and Calgary Rehabilitation Database and then transferred to the authors following appropriate ethics and administrative approvals.

\section{Data Analysis}

The mean, median, and standard deviation were calculated for continuous variables and frequency distribution and percentages for categorical variables. The independent-samples $t$-test was used to examine the difference in length of time since stroke, as well as the differences in FIM change and in LOS in inpatient rehabilitation for male and female stroke patients. Differences in LOS in rehabilitation for patients younger than 65 years and patients $65+$ years were also examined. Analysis of variance was used to test main and interaction effects of time since stroke and 
Table 1: Demographic characteristics of subjects

\begin{tabular}{|c|c|c|c|c|}
\hline Characteristics & Total & Mild stroke & Moderate stroke & Severe stroke \\
\hline \multicolumn{5}{|c|}{ Age at acute care admission (years) } \\
\hline Median (interquartile range) & $69(67-71)$ & $67(58-76)$ & $71(60-81)$ & $71(59-82)$ \\
\hline \multicolumn{5}{|l|}{$\operatorname{Sex}(\%)$} \\
\hline Male & 56.6 & 61.1 & 51.0 & 59.8 \\
\hline Female & 43.4 & 38.9 & 49.0 & 40.2 \\
\hline \multicolumn{5}{|l|}{ Etiology of stroke (\%) } \\
\hline Ischemic stroke & 83.4 & 85.5 & 82.3 & 70.9 \\
\hline Hemorrhagic stroke & 16.6 & 14.5 & 17.7 & 29.1 \\
\hline
\end{tabular}

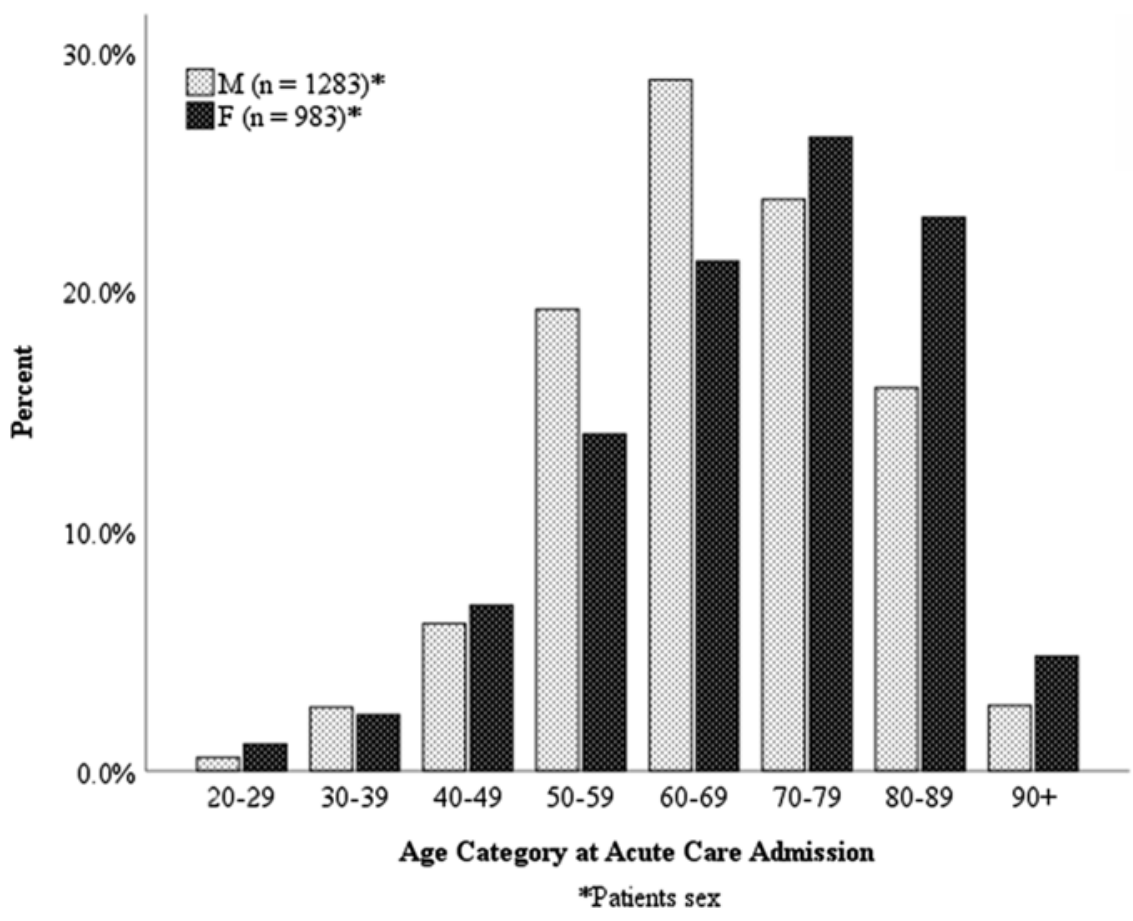

Figure 1: Bars chart of age category (in years) at acute care admission by patient's sex. The height of the bar represents percentage of cases that were in the corresponding age category at acute care admission, and the color of the bar represents the sex of the patients.

patient's sex on FIM change (including motor and cognitive), and the main and interaction effects of age and patient's sex on LOS in inpatient rehabilitation. Chi-square tests were used to examine the relationship between patient's sex and stroke severity; patient's sex and patient's living arrangement at discharge from rehabilitation; patient's sex and post discharge living setting; and age and post discharge living setting.

\section{Results}

The sample consisted of 2266 (male $=1283$, female $=983$ ) patients admitted to and discharged from inpatient stroke rehabilitation units in Alberta between April 2013 and March 2017 (see Table 1). These were clinically diagnosed cases of adult stroke (ischemic or hemorrhagic) subcategorized as mild, moderate, or severe impaired based on their initial FIM score at acute care admission. The mean LOS for active inpatient rehabilitation was 65.9 d (45 median; 66.2 SD), and the mean FIM change for all participants was 23.7 (22 median; 15.8 SD). We examined the relationship between patient's sex and patient's age (in years) at acute care admission (see Figure 1). The mean age was 67 (13 SD) for male stroke patients and 69 (15 SD) for female stroke patients, with overall mean age at acute care admission across both males and females of 68 (14 SD). To determine whether the distribution of age was the same for both males and females, we performed a two samples Kolmogorov-Smirnov test. We observed a statistically significant difference $\left(p=2.2 \times 10^{-4}\right)$ in age distributions between male and female patients. To determine whether there were significant differences in age at acute care admission, we performed an independent-samples t-test. We observed a significant difference 


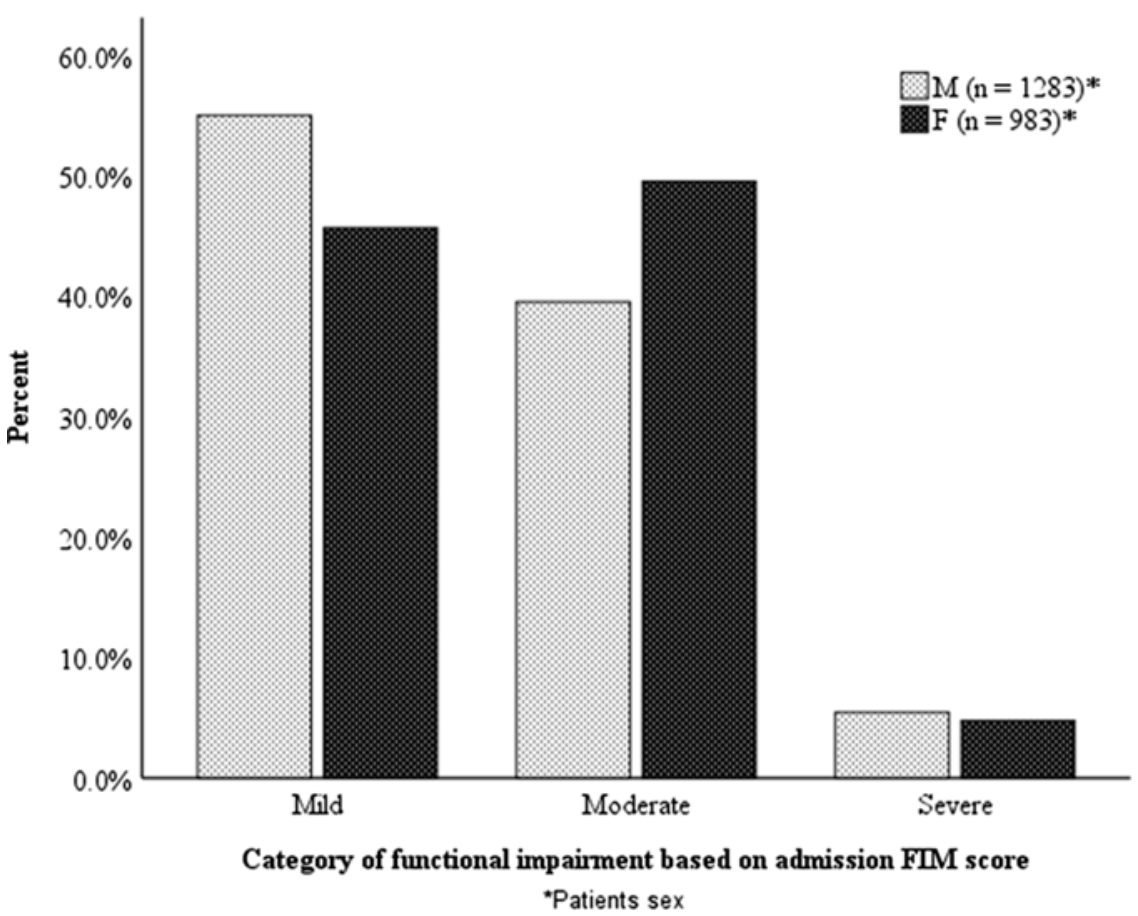

Figure 2: Bars chart of category of functional impairment based on admission Functional Independence Measure score by patient's sex. The height of the bar represents percentage of cases that were in the corresponding category of functional impairment, and the color of the bar represents the sex of the patients.

in age for males and females $\left(\mathrm{t}(1999)=-3.69, p=2.4 \times 10^{-4}\right.$, two-tailed). The magnitude of the differences in the means (mean difference $=-2.19,95 \% \mathrm{CI}$ : -3.36 to -1.03 ) was small (Cohen's $d=-0.14$ ). This finding implies that the age of male and female stroke patients differed slightly at the start of the acute stroke episode of care, with males being younger than females.

\section{Is Patient's Sex Associated with Stroke Severity at Admission to Inpatient Rehabilitation?}

We examined the relationship between patient's sex and stroke severity based on admission FIM score (see Figure 2). The mean admission FIM score was 81.46 (23.06 SD) for male stroke patients and 77.66 (21.64 SD) for female stroke patients, with overall mean admission FIM score of 79.81 (22.53 SD). At admission to inpatient rehabilitation, $55 \%$ of male stroke patients (45.7\% females) had mild stroke, $39.5 \%$ of males $(49.5 \%$ of females) had moderate stroke, and $5.5 \%$ of males $(4.8 \%$ females) had severe stroke. To determine whether these proportions of males and females (based on admission FIM scores) differed significantly, we used a chisquare test for independence which indicated a statistically significant association between sex and stroke severity, $\chi^{2}(2, n=2266)$ $=22.79, p=0.000011$, Cramer's $v=0.1$, with a small effect size.

\section{Is There an Association between Patient's Sex and Time between Stroke Onset and Rehabilitation Admission?}

We examined the relationship between patient's sex and time since stroke (length of time from acute care admission to inpatient rehabilitation admission) (see Figure 3). The mean time since stroke (in days) to rehabilitation admission was 22.48 (25.78 SD) for male stroke patients and 22.86 (26.33 SD) for female stroke patients, with overall mean time since stroke across both males and females of 22.64 (26.01 SD). To determine whether there were significant differences in time since stroke between male and female patients, we performed an independent-samples t-test. We observed no significant difference in time since stroke for males and females $(\mathrm{t}(2264)=-0.35, p=0.73$, two-tailed). The magnitude of the differences in the means (mean difference $=$ $-0.38,95 \%$ CI: $-2.54-1.78$ ) was very small (Cohen's $d=-0.01$ ).

\section{Are Patient's Sex and Time between Stroke Onset and Rehabilitation Admission Related to Functional Gains During Rehabilitation?}

We examined the impact of time from acute care admission to inpatient rehabilitation admission on functional changes during rehabilitation. The mean FIM change during inpatient rehabilitation was 23.39 points for male stroke patients (21 median; $15.78 \mathrm{SD}$ ) and 24.09 points for female stroke patients (22.0 median; 15.9 SD), with overall mean FIM change of 23.7 (15.83 SD). To further determine the differences in FIM change between male and female stroke patients, we conducted an independent-samples t-test to compare the mean FIM changes between male and female stroke patients. There was no significant difference in mean FIM change between males and females $(\mathrm{t}(2264)=-1.049, p=0.294$, two-tailed $)$.

We further examined FIM efficiency to understand how male and female stroke patients were improving in their functional abilities during each day of rehabilitation. There was no significant difference in mean FIM efficiency between males $(M=0.51$, 


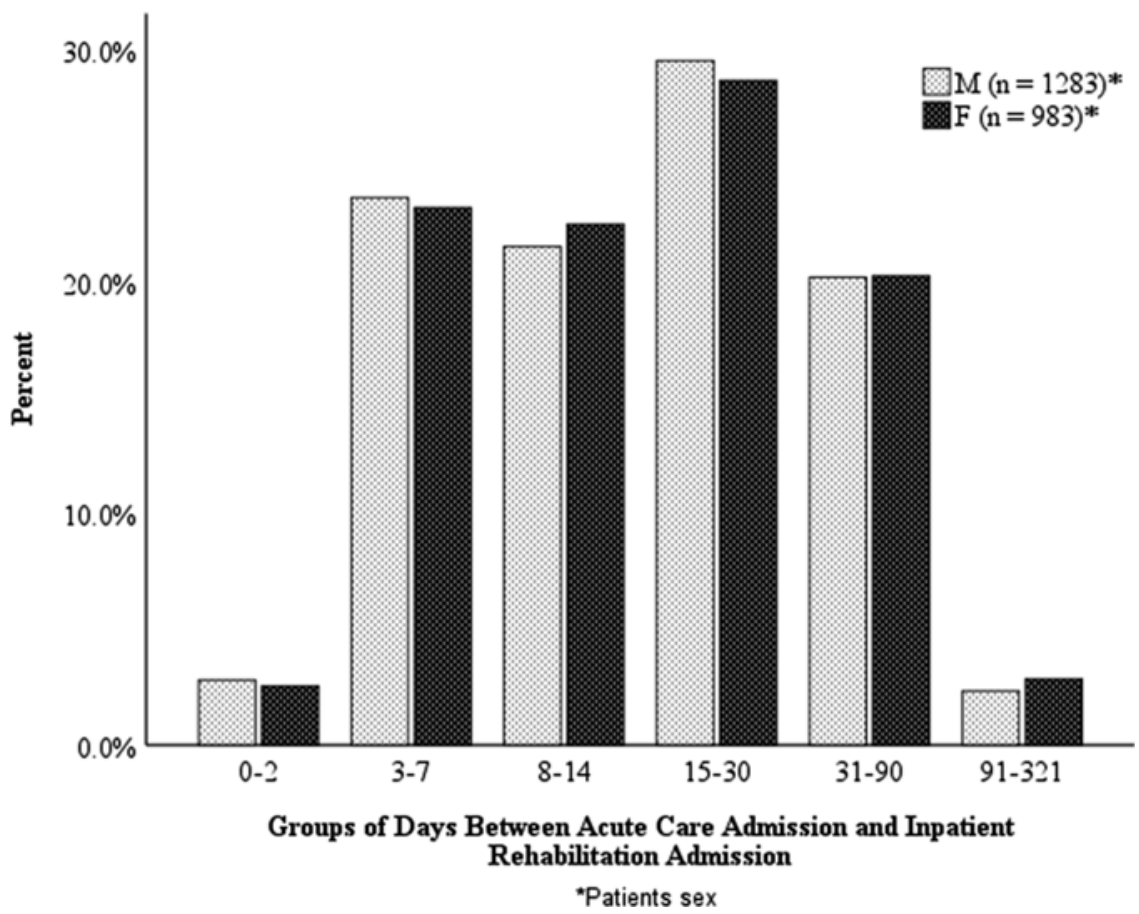

Figure 3: Bars chart of groups of days between acute care admission and inpatient rehabilitation admission by patient's sex. The height of the bar represents percentage of cases that waited for the corresponding number of days between acute care admission and impatient rehabilitation admission, and the color of the bar represents the sex of the patients.

$0.40 \mathrm{SD})$ and females $(M=0.53,0.87 \mathrm{SD} ; \mathrm{t}(2264)=-0.597$, $p=0.550$, two tailed).

\section{Does Patient's Sex Influence Rehabilitation Length of Stay?}

We examined the relationship between patient's sex and LOS in inpatient rehabilitation (see Figure 4). The mean LOS (in days) in inpatient rehabilitation was 63.0 (44 median; 64.3 SD) for male stroke patients and 69.7 (47 median; 68.5 SD) for female stroke patients, with overall LOS of 65.9 (45 median; $66.2 \mathrm{SD}$ ). We observed a significant difference in mean LOS in rehabilitation for males $(M=63.0,64.3 \mathrm{SD})$ and females $(M=69.7,68.5 \mathrm{SD})$; $\mathrm{t}(2042)=-2.36, p=0.02$, two-tailed). The magnitude of the differences in the means (mean difference $=-6.67,95 \%$ CI: -12.21 to -1.13 ) was very small (Cohen's $d=-0.1$ ).

\section{How Are Patient's Sex and Age at Acute Care Admission Related to Length of Stay in Rehabilitation?}

We wished to determine whether patient's age had a substantial impact on LOS in rehabilitation. The mean LOS (in days) in inpatient rehabilitation was significantly longer for those under 65 years $(M=78.56,87.84 \mathrm{SD})$ than those over 65 years $\left(M=57.80,45.84 \mathrm{SD} ; \mathrm{t}(1187)=6.47, p=1.4 \times 10^{-10}\right.$, two-tailed $)$. The magnitude of the differences in the means (mean difference $=20.75,95 \%$ CI: 14.46 to 20.05 ) was small (Cohen's $d=0.3$ ). Further, we wanted to determine the effects of patient's sex and age on LOS in rehabilitation and also determine whether these effects on LOS differed significantly between the different age groups. Thus, we ran a two-way between-groups analysis of variance, which demonstrated no interaction effect on LOS $(\mathrm{F}(7,2250)=1.051, p=0.39)$ and no main effect for sex
$(\mathrm{F}(1,2250)=0.721, p=0.396)$. But there was a significant main effect for age $\left(\mathrm{F}(7,2250)=10.80, p=1.9 \times 10^{-13}\right)$ with a very small effect size (partial eta squared $=0.03$ ).

\section{Is Patient's Sex Associated with Discharge Destination?}

We wanted to determine whether patient's sex had an influence on their post discharge living setting, so we examined the relationship between sex and post discharge living setting (see Figure 5). At discharge from inpatient rehabilitation, 55.5\% of male stroke patients were discharged home with no health services compared to $44.6 \%$ of females. With regard to other dispositions, $32.3 \%$ of female stroke patients ( $28.4 \%$ males) were discharged home with paid health services, $10.4 \%$ (6.4\% males) were discharged to assisted living, and $9.1 \%$ (5.9\% males) were discharged to residential care. Results of Chi-square test for independence indicated a statistically significant association between patient's sex and post discharge living setting, $\chi^{2}$ $(4, n=2266)=34.31, p=6.4 \times 10^{-7}$, Cramer's $v=0.12$, with a small effect size. This finding implies that patient's sex had a small influence on their discharge destination.

To determine whether a patient's living setting prior to rehabilitation admission potentially influenced their post rehabilitation discharge living setting, we started by examining the relationship between patient's sex and patient's living setting at admission to inpatient rehabilitation. At acute care admission $58.7 \%$ of male compared to $41.3 \%$ of female stroke patients were living at home with no health services. With regard to other living settings, $40.3 \%$ of male stroke patients ( $49.7 \%$ females) were living at home with paid health services, $33.0 \%$ (67.0\% females) were living in assisted living, and $36.4 \%$ (63.6\% females) were living in residential care. 


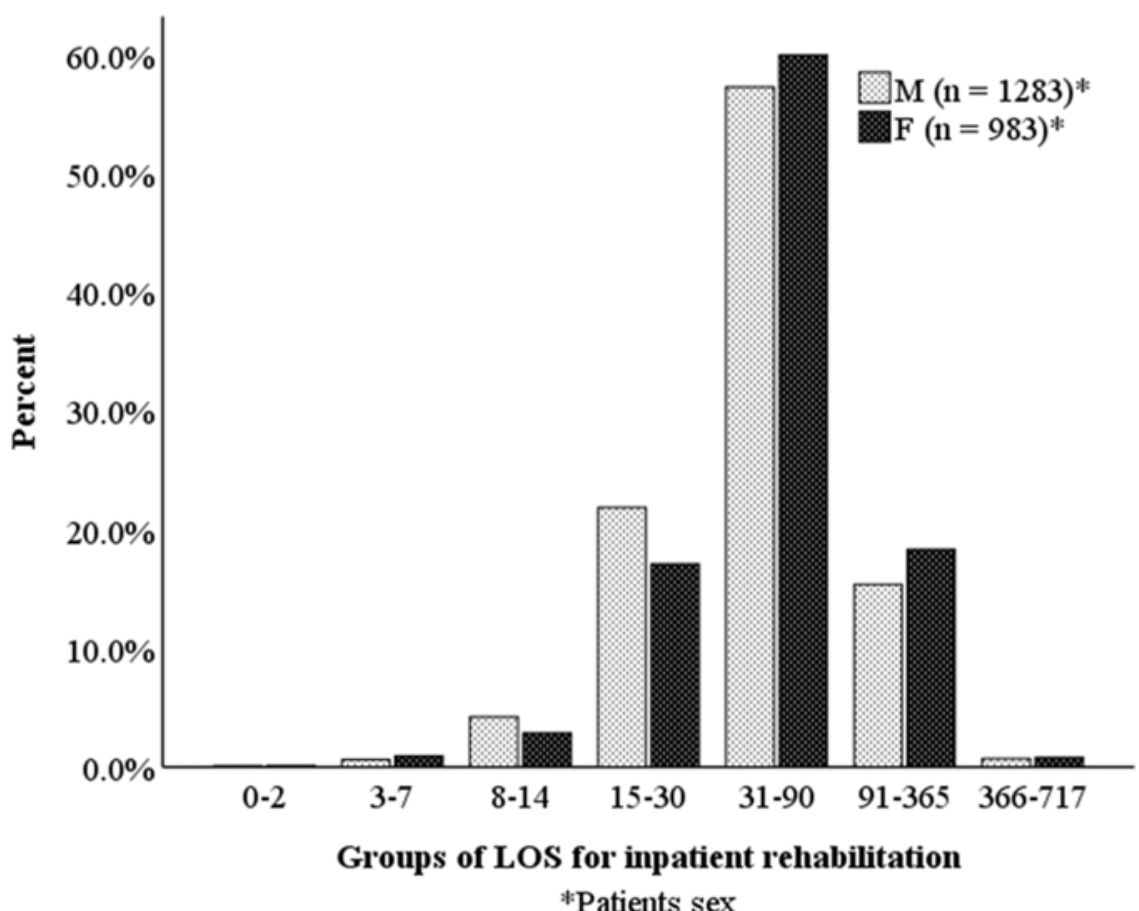

Figure 4: Bars chart of groups of length of stay (days) for inpatient rehabilitation by patient's sex. The height of the bar represents percentage of cases that spent the corresponding number of days in inpatient rehabilitation, and the color of the bar represents the sex of the patients.

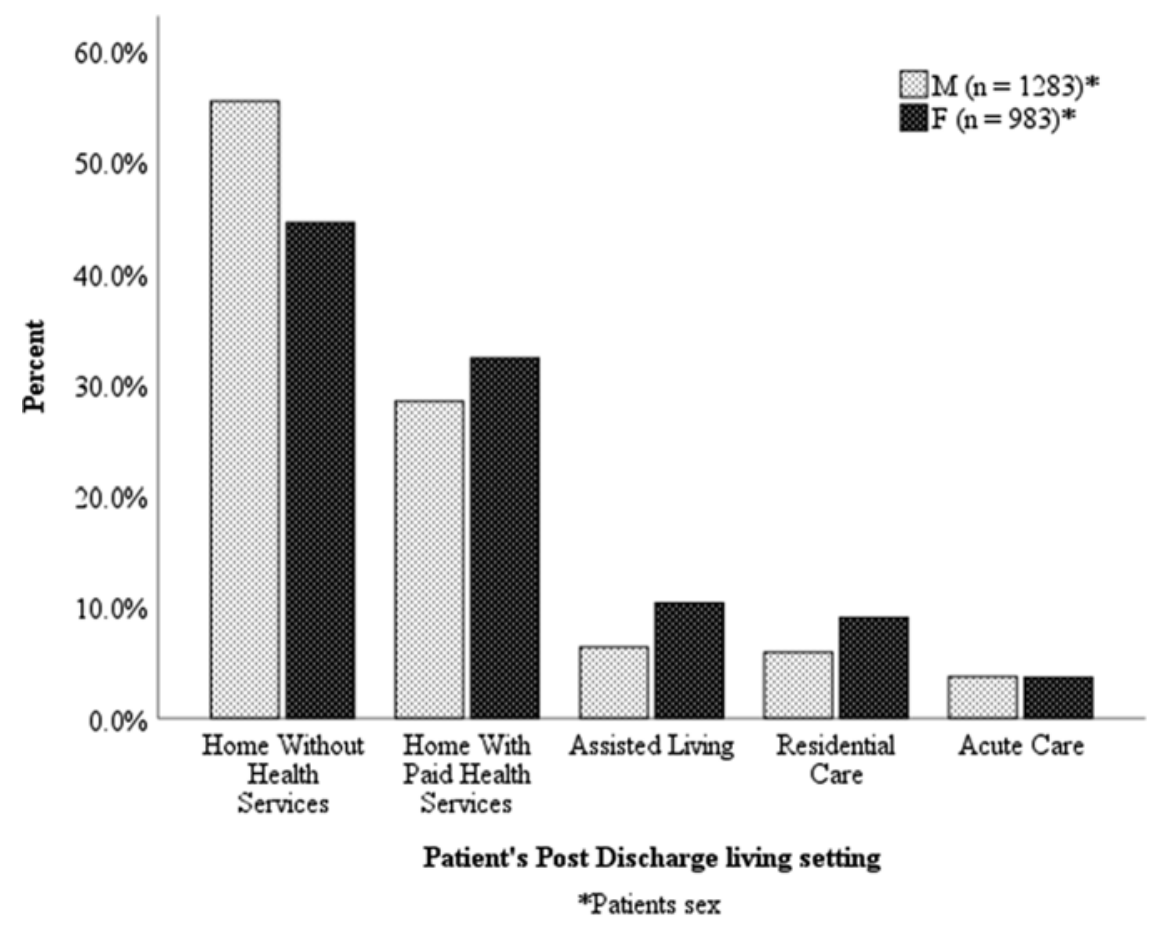

Figure 5: Bars chart of post discharge living settings by patient's sex. The height of the bar represents percentage of cases that were discharged to the corresponding post discharge living setting, and the color of the bar represents the sex of the patients. 


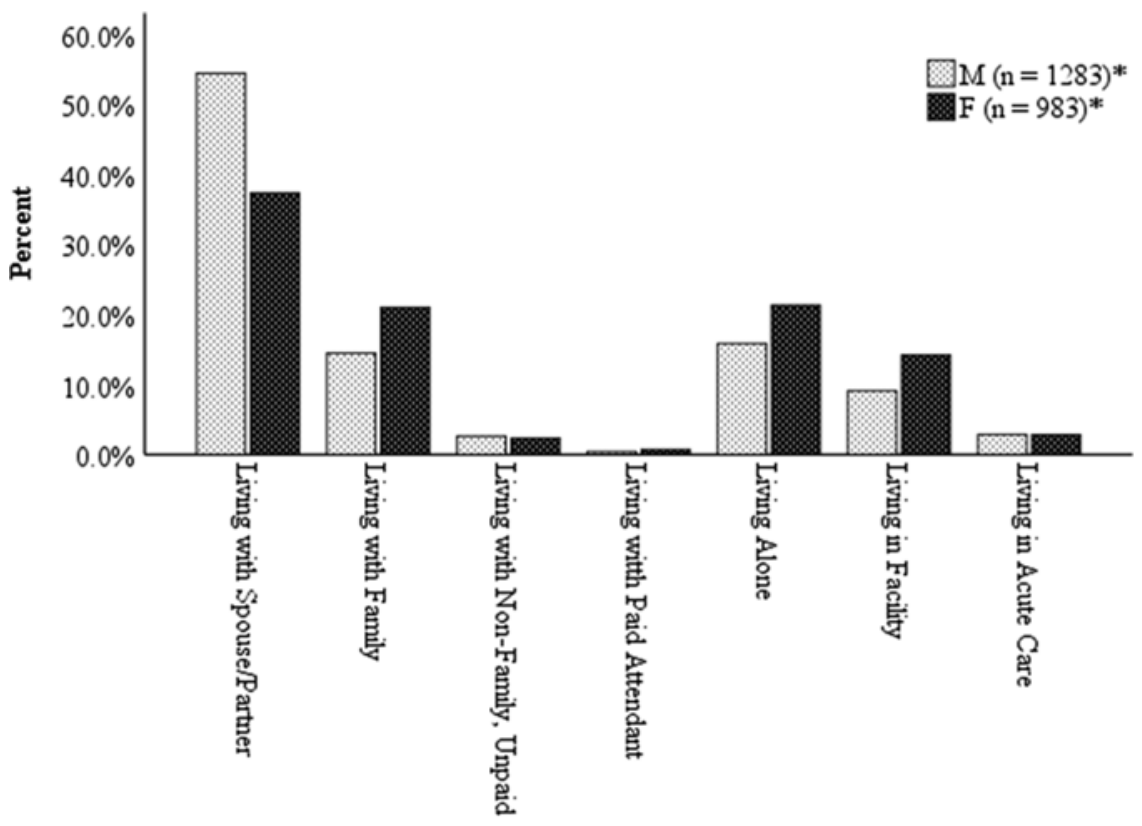

Patient's Living Arrangements at Discharge From Rehabilitation

*Patients sex

Figure 6: Bars chart of living arrangements at discharge from inpatient rehabilitation facility by patient's sex. The height of the bar represents percentage of cases that had the corresponding living arrangement, and the color of the bar represents the sex of the patients.

From these findings, male stroke patients were more likely to be living at home without health services (homecare) compared to female stroke patients. Conversely, female stroke patients were more likely to be living at home with homecare or living in assisted living, and residential care compared to male stroke patients. A chisquare test for independence indicated a statistically significant association between patient's sex and patient's living setting at inpatient rehabilitation admission, $\chi^{2}(3, n=2266)=39.11$, $p=1.6 \times 10^{-8}$, Cramer's $v=0.13$, with a small to effect size. This finding implies that patient's sex had a small to moderate influence on their living setting at inpatient rehabilitation and that living setting prior to rehabilitation admission differed between male and female stroke patients.

\section{Is Patient's Sex Associated with Patients' Living Arrangement at Discharge from Inpatient Rehabilitation?}

We also wanted to determine whether patient's living arrangement at discharge from inpatient rehabilitation had an influence on their discharge destination. We started by examining the relationship between patient's sex and patient's living arrangement at discharge from inpatient rehabilitation (see Figure 6). At discharge from rehabilitation, $15.9 \%$ of male relative to $21.4 \%$ of female stroke patients were living alone. Conversely, $54.6 \%$ of male compared to $37.4 \%$ of female stroke patients were living with spouses/partners. Also, $14.5 \%$ of males $(21.1 \%$ females $)$ were living with family, and $9.1 \%$ of males ( $14.2 \%$ females) were living in a facility. A Chisquare test for independence indicated a statistically significant association between sex and patient's living arrangement at discharge from rehabilitation, $\chi^{2}(6, n=2266)=71.72, p=1.8 \times 10^{-13}$,
Cramer's $v=0.18$, with a medium to large effect size. These findings imply that patient's sex and their living arrangement are related as female stroke patients were discharged to situations where they were living alone, living with the family, or living in facility compared to male stroke patients who were more likely to be discharged to situations where they were living with spouse/ partner.

\section{Is Age Associated with Discharge Destination Following Inpatient Stroke Rehabilitation?}

Finally, we examined the relationship between age and post discharge living setting (see Figure 7). We observed that $62.8 \%$ of patients younger than 65 years were more likely to be discharged home without health services compared to $43.1 \%$ of patients $65+$ years. Conversely, $31.8 \%$ of patients $65+$ years ( $27.5 \%$ younger than 65 years) were more likely to be discharged home with paid health services, $11 \%$ (3.6\% younger than 65 years) discharged to assisted living, $9.2 \%$ (4.3 younger than 65 years), discharge to residential care, and $5.0 \%$ (1.7\% younger than 65 years) discharged back to acute care. A Chi-square test for independence indicated a statistically significant association between age and post discharge living setting, $\chi^{2}(4, n=2266)$ $=113.31, p=1.4 \times 10^{-23}$, Cramer's $v=0.224$, with a large effect size. This finding means that patient's age and discharge destination are related as patients under 65 years were more likely to be discharged home without needing health services, and patients aged 65 years and older were more likely to be discharged home with paid health services or discharged to living settings where additional care is provided. 


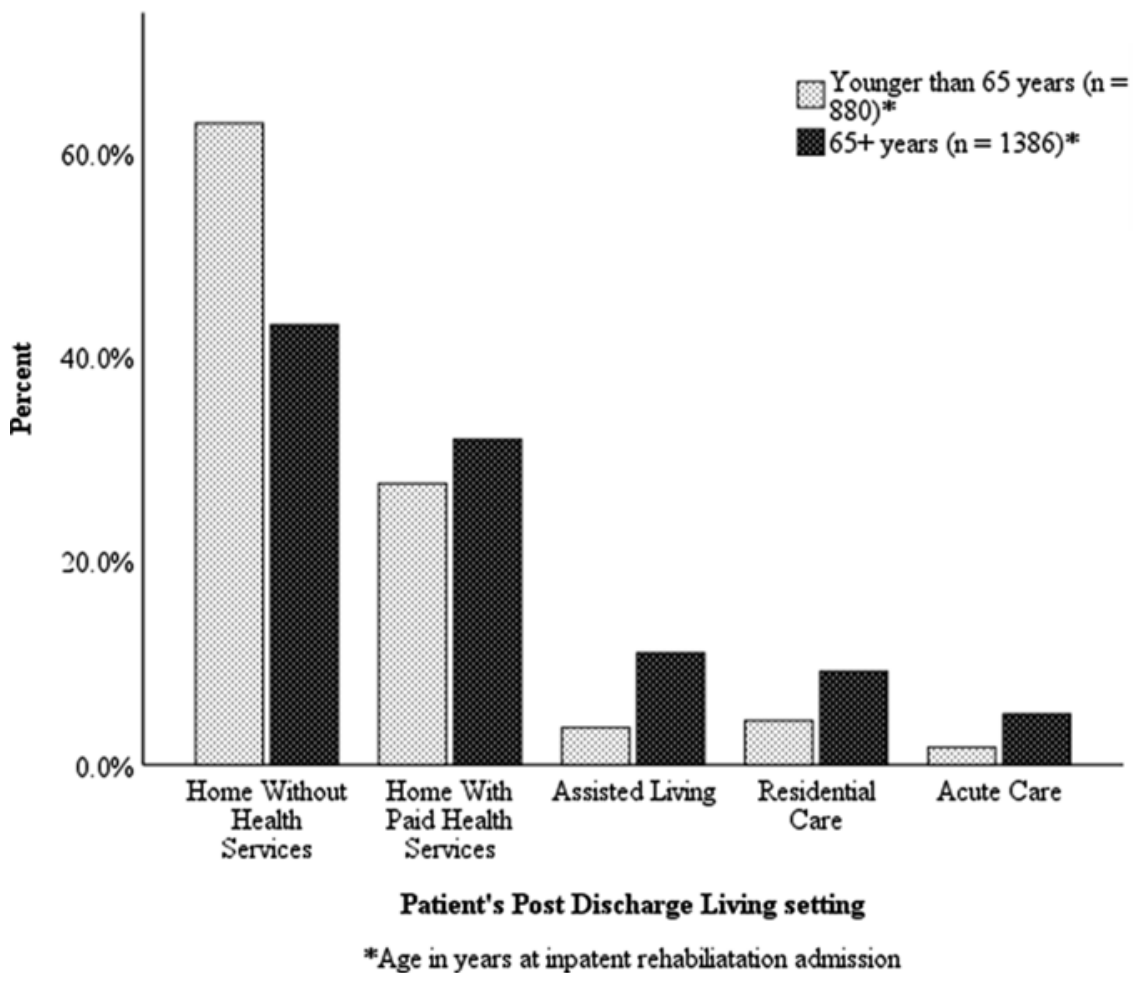

Figure 7: Bars chart of patient's post discharge living setting by patient's age category (in years) at acute care admission. The height of the bar represents percentage of cases that were discharged to the corresponding post discharge living setting, and the color of the bar represents the age category of the patients.

\section{Discussion}

\section{Summary of Key Points}

We conducted a province-wide analysis of primary data from a large sample of patients admitted to and discharged from inpatient stroke rehabilitation units in Alberta between April 2013 and March 2017. Female patients tended to have a longer LOS in rehabilitation compared to male stroke patients. Male stroke patients and patients $<65$ years were more likely to be discharged home without needing health services, while female stroke and patients $\geq 65$ years were more likely to be discharged home with paid health services, assisted living, residential care, and back to acute care. There was no significant difference in mean time to rehabilitation admission and mean FIM gain between male and female stroke patients.

\section{Impact of Patient's Sex on Functional Outcomes}

Female stroke patients in Alberta had longer mean LOS in rehabilitation and were more likely to be discharged home with paid health services relative to males. This finding was similar to findings reported in Ontario ${ }^{15}$ and could be attributed to the fact that female stroke patients are older, have more physical limitations, suffer depression, social isolation, or lack of social support, and are more likely to be widowed. ${ }^{2,16}$ The fact that females, on average, began rehabilitation with lower FIM scores may have impacted their rehabilitation LOS/outcomes in the current study. Other factors that may contribute to poorer outcomes in females are decreased physical function prior to rehabilitation admission, reduced independence in performance of daily living activities, ${ }^{2,4}$ history of stroke, increased body mass index, increased stroke severity, and nursing home residence prior to stroke onset. ${ }^{11}$ Differences in participation tolerance, although not measured in the present study, is a factor that could also contribute to poorer outcomes in females as decreased participation in physical activity or exercise after stroke can lead to increased disability, dependence, and mortality, as well as decreased quality of life. ${ }^{17}$ Further, in other studies, males have demonstrated greater independence in stair climbing and performance of daily living activities compared to females. ${ }^{3,5,9}$ This has been attributed to increased androgen receptors and higher levels of testosterone that stimulate muscle development and increase muscle mass in males compared to females. ${ }^{10}$ This difference between male and female stroke patients suggest that there is a need for rehabilitation professionals to refine programs that provide social (pragmatic) support (emotional, informational, companionship, and financial support ${ }^{18}$ ) to female stroke patients.

\section{Impact of Patient's Age on Functional Outcomes}

Patients $<65$ years are more likely to be discharged home without needing health services, while older patients $\geq 65$ years are more likely to be discharged home with paid health services, assisted living, residential care, and back to acute care. This finding may be attributed to the physical limitations, disability, and loss of independence experienced by older patients. ${ }^{19}$ 
Patients $<65$ years are more likely to have longer LOS in rehabilitation compared to those $\geq 65$ years. This finding has been previously attributed to multiple factors including "performance bias," a situation where rehabilitation staff have lower expectations of functional gains for older patients, resulting in shorter LOS in rehabilitation for older patients. ${ }^{20}$ Other factors that may explain this finding are "premature discharge," a situation whereby older patients are discharged from rehabilitation early due to decreased physical ability to participate in rehabilitation, a request by family for patient to be discharged, or transfer of patient back to acute care. ${ }^{21}$ Larger functional gains have been reported among younger stroke patients following inpatient rehabilitation compared to older stroke patients. ${ }^{22,23}$ This may be attributed to longer rehabilitation LOS among younger stroke patients.

\section{Impact of Patient's Living Arrangement at Discharge from Rehabilitation on Functional Outcomes}

Patient's living arrangement prior to having the stroke had an influence on post discharge living setting. The majority of patients in this cohort who were living alone prior to stroke were females and were more likely to discharge home with paid health services, assisted living, and residential care, compared to majority of patients (males) who were living with spouse/partner and were more likely to discharge home without needing health services. Female stroke patients are more likely to be widowed or living without a spouse or partner. Stroke patients who are living with a spouse/partner or living with family may receive help from these individuals in performing daily living activities. Clinicians often consider having someone at home who is willing to assume the caregiver role as an important factor in discharge planning as it is perceived to increase patient safety.

\section{Comparison to Another Province in Canada}

When we compared findings from this study to those reported in other Canadian provinces, we observed certain similarities and differences. For the similarities, the majority of stroke patients admitted to inpatient rehabilitation units in both Ontario ${ }^{15}$ and Alberta were males compared to females. Of those admitted to rehabilitation in both provinces, female stroke patients had a higher level of disability/dependence (based on admission FIM score) at the time of admission to rehabilitation compared to male stroke patients. With respect to age, female stroke patients in both Ontario and Alberta were older at the time of admission to inpatient rehabilitation. Further, similar sex differences in discharge destination of stroke patients were noted in the two provinces. In Ontario, male stroke patients were more likely to be discharged home without health services compared to female stroke patients who were more likely to be discharged home with community health services or to a long-term care facility. ${ }^{15}$ Similar to Ontario, our Alberta data demonstrate that male stroke patients were more likely to be discharged home without needing health services, and female stroke patients were more likely to be discharged home with paid health services, or to assisted living or residential care. With respect to stroke patients' LOS in rehabilitation, female stroke patients in both Ontario and Alberta had longer LOS in rehabilitation than male stroke patients. The main difference between Ontario (31 d) and Alberta (45d) was the overall median LOS in rehabilitation. ${ }^{24}$
In Ontario, Quality Based Procedures (QBP) have had a significant impact on LOS, whereas no such process exists in Alberta. QBP sets target LOS in inpatient rehabilitation for stroke patients based on Rehabilitation Patient Group (RPG) designations for mild, moderate, and severe stroke. The RPG calculation accounts for the patient's age, motor and cognitive functional status, but not sex. RPG stratification produces several different patient groupings, each with an estimated LOS to which rehabilitation centers are encouraged to adhere. As examples, median LOS for inpatient rehabilitation in a mild stroke (RPG 1150) would be $7.7 \mathrm{~d}$, whereas a moderate stroke (RPG 1130) would be $25.2 \mathrm{~d}$ and a severe stroke (RPG 1100) would be 48.9 d. ${ }^{15}$ In our discussions with clinicians from Ontario, the RPG process and the alignment of hospital program funding to this process have led to a significant shortening of inpatient stroke LOS over the past several years.

\section{Opportunities for Change}

As demonstrated in this study, LOS in rehabilitation is generally long, with females and younger patients experiencing longer LOS. We hope that our findings will help clinicians reassess Alberta Health Services' stroke rehabilitation system/ processes to determine specific factors that drive LOS in rehabilitation in Alberta and to make appropriate changes to improve functional outcomes of stroke patients in Alberta. Potential factors, such as "performance bias" (lowering functional gains expectations for older stroke patients during rehabilitation), capacity issues, and staff opinions regarding patient's readiness to return home or advance to the next phase of rehabilitation would need to be investigated and addressed. Other factors that may be contributing to longer rehabilitation LOS in Alberta, in our opinion, are the absence of benchmark policy for stroke patient's LOS in rehabilitation and challenges with geography with great distances between rehabilitation facilities (particularly in Northern Alberta). Shortage of staff in some facilities, difficulties accessing outpatient rehabilitation services, and psychosocial problems (such as broken marriages, childcare responsibilities, and inability to resume previous employment) may also contribute to longer rehabilitation $\operatorname{LOS}^{25}$

\section{Limitations of This Study}

There were certain limitations to this study. The accuracy of FIM scores recorded by therapy staff and the individuals who enter information at each hospital in Alberta could not be ascertained. However, all individuals administering the FIM do complete biennial certification to administer it. A ceiling effect has been demonstrated for FIM Score ${ }^{26}$ and has the potential to limit the ability to accurately measure patient improvement in the case of mild stroke patients. Further data from other commonly used measures such as the National Institutes of Health Stroke Scale or other disability measures might have helped to enrich the current data set but are not currently collected in our provincial database. Lastly, the fact that data are from a single province limits generalizability of findings to other provinces.

\section{Conclusions}

Our study offers a clear picture of the influence of patient's sex on inpatient stroke rehabilitation care in Alberta from 2013 to 2017. We evaluated whether there were differences in stroke rehabilitation outcomes (functional gains, LOS, and discharge 
destination) based on patient's sex and whether the time from acute care admission to inpatient rehabilitation differed between male and female stroke patients. Further, we examined whether patient's sex, age, and patient's living arrangement had an influence on discharge destination. Length of time to rehabilitation admission and functional gains did not differ between male and female stroke patients. Stroke in males was associated with younger age ( $<65$ years), shorter rehabilitation LOS, living with a spouse or partner, and discharge home without health services. Stroke in females was associated with older age (65+ years), slightly longer rehabilitation LOS, living alone at discharge from rehabilitation, and discharge to home with paid health services.

\section{ACKNowledgments}

The authors acknowledge the help they received from Flora Stephenson, Janice Yajure, Natasha Mcguire, Agnes Lehman, and the entire Data Integration, Measurement, and Reporting Data Governance Team at Foothills Medical Centre who assisted them with data acquisition.

\section{Disclosures}

ET, KK-S, TG, CS, and SD have no conflicts of interest to disclose.

\section{Statement of Authorship}

ET contributed to the concept, design, data acquisition, data analysis, interpretation, and drafting of the manuscript.

KK-S contributed to the design, data acquisition, data analysis, interpretation, supervision, critical reviews, and final approval of the manuscript.

TG contributed critical reviews for intellectual content and final approval of the manuscript.

CS contributed critical reviews for intellectual content and final approval of the manuscript.

SD contributed to the design, data acquisition, data analysis, interpretation, supervision, critical reviews, and final approval of the manuscript.

\section{REFERENCES}

1. Holroyd-Leduc JM, Kapral MK, Austin PC, Tu JV. Sex differences and similarities in the management and outcome of stroke patients. Stroke. 2000;31(8):1833-7.

2. Kapral MK, Fang J, Hill MD, et al. Sex differences in stroke care and outcomes: results from the registry of the Canadian stroke network. Stroke. 2005;36(4):809-14

3. Paolucci S, Bragoni M, Coiro P, et al. Is sex a prognostic factor in stroke rehabilitation? A matched comparison. Stroke. 2006; 37(12):2989-94.

4. Denti L, Artoni A, Scoditti U, et al. Impact of gender-age interaction on the outcome of ischemic stroke in an Italian cohort of patients treated according to a standardized clinical pathway. Eur J Intern Med. 2013;24(8):807-12.

5. Glader EL, Stegmayr B, Norrving B, et al. Sex differences in management and outcome after stroke: a Swedish national perspective. Stroke. 2003;34(8):1970-5.

6. Olsen TS, Andersen ZJ, Andersen KK. Explaining poorer stroke outcomes in women: women surviving 3 months have more severe strokes than men despite a lower 3-month case fatality. Gend Med. 2012;9(3):147-53.
7. Reeves MJ, Bushnell CD, Howard G, et al. Sex differences in stroke: epidemiology, clinical presentation, medical care, and outcomes. Lancet Neurol. 2008;7(10):915-26.

8. Sue-Min L, Duncan PW, Dew P, Keighley J. Peer reviewed: sex differences in stroke recovery. Prev Chronic Dis. 2005;2(3): $1-11$.

9. Wu X, Min L, Cong L, et al. Sex differences in health-related quality of life among adult stroke patients in Northeastern China. J Clin Neurosci. 2014;21(6):957-61.

10. Gentil P, Steele J, Pereira MC, Castanheira RP, Paoli A, Bottaro M. Comparison of upper body strength gains between men and women after 10 weeks of resistance training. Peer J. 2016;4: e1627.

11. Lisabeth LD, Reeves MJ, Baek J, et al. Factors influencing sex differences in poststroke functional outcome. Stroke. 2015; 46(3):860-3.

12. Stineman MG, Fiedler RC, Granger CV, Maislin G. Functional task benchmarks for stroke rehabilitation. Arch Phys Med Rehabil. 1998;79(5):497-504.

13. Ween JE, Alexander MP, D'Esposito M, Roberts M. Factors predictive of stroke outcome in a rehabilitation setting. Neurology. 1996;47(2):388-92.

14. Graham JE, Granger CV, Karmarkar AM, et al. The uniform data system for medical rehabilitation: report of follow-up information on patients discharged from inpatient rehabilitation programs in 2002-2010. Am J Phys Med Rehabil. 2014; 93(3):231.

15. Hall RE, French E, Khan F. Ontario stroke evaluation report 2016: a focus on stroke rehabilitation. Toronto: Institute for Clinical Evaluative Sciences; 2016.

16. Koton S, Telman G, Kimiagar I, Tanne D, National Acute Stroke Israeli Survey Investigators. Gender differences in characteristics, management and outcome at discharge and three months after stroke in a national acute stroke registry. Int J Cardiol. 2013; 168(4):4081-4.

17. Saunders DH, Greig CA, Mead GE. Physical activity and exercise after stroke: review of multiple meaningful benefits. Stroke. 2014;45(12):3742-7.

18. Blessing $\mathrm{M}$, Oluwagbemiga $\mathrm{O}$. Effectiveness of social support in coping with stroke by medically ill patient in Ibadan. Int $\mathbf{J}$ Neurorehabil. 2017;4(04):2376-0281.

19. Paterson DH, Warburton DE. Physical activity and functional limitations in older adults: a systematic review related to Canada's physical activity guidelines. Int $\mathbf{J}$ Behav Nutr Physical Act. 2010;7(1):38.

20. Elwood D, Rashbaum I, Bonder J, et al. Length of stay in rehabilitation is associated with admission neurologic deficit and discharge destination. Phys Med Rehabil. 2009;1(2):147-51.

21. Atalay A, Turhan N. Determinants of length of stay in stroke patients: a geriatric rehabilitation unit experience. Int $\mathbf{J}$ Rehabil Res. 2009;32(1):48-52.

22. Cotoi A, Batey C, Hussein N, Janzen S, Teasell R. Rehabilitation of younger patients post stroke. In: The Stroke Rehabilitation Evidence-Based Review. Available at: www.ebrsr.com; accessed September 30, 2019.

23. Teasell R, Hussein N, Foley N. Managing the stroke rehabilitation triage process. In: The Stroke Rehabilitation Evidence-Based Review. Available at: www.ebrsr.com; accessed November 2, 2019.

24. Grant $\mathrm{C}$, Goldsmith $\mathrm{CH}$, Anton HA. Inpatient stroke rehabilitation lengths of stay in Canada derived from the national rehabilitation reporting system, 2008 and 2009. Arch Phys Med Rehabil. 2014; 95(1):74-8.

25. Teasell RW, McRae MP, Finestone HM. Social issues in the rehabilitation of younger stroke patients. Arch Phys Med Rehabil. 2000;81(2):205-9.

26. Kwon S, Hartzema AG, Duncan PW, Min-Lai S. Disability measures in stroke: relationship among the barthel index, the functional independence measure, and the modified Rankin scale. Stroke. 2004;35(4):918-23. 